\title{
RIP1 expression is necessary for CD30-mediated cell death induction in anaplastic large-cell lymphoma cells
}

\author{
Burkhard Hirsch ${ }^{1}$, Edda von der Wall ${ }^{1}$, Michael Hummel ${ }^{1,3}$ and Horst Dürkop ${ }^{2,3}$
}

CD30, a member of the tumor necrosis factor receptor (TNFR) superfamily, is consistently expressed by tumor cells of anaplastic large-cell lymphoma (ALCL). CD30 stimulation induces massive caspase-dependent cell death of ALCL cells in case of canonical NF $\kappa$ B inhibition or proteasome inhibition. However, CD30, a TNFR lacking a death domain (DD), is unable to recruit a death inducing complex containing TRADD (TNFR1-associated DD-protein) or FADD (FAS-associated DD-domain protein) together with the receptor-interacting protein 1 (RIP1) and caspase-8. Thus, the mechanism explaining CD30-induced cell death of lymphocytes remains obscure. Here, we demonstrate that blockage of RIP1 by siRNA or pharmacological inhibition of RIP1 by Necrostatin-1 almost completely prevented CD30-induced cell death. In addition, we revealed CD30-induced accumulation of RIP1 at the cytoplasma membrane of NF $\kappa$ B-inhibited $\mathrm{ALCL}$ cells by confocal laser scanning microscopy. Finally, primary $A L C L$ cases can be subdivided into two groups based on the presence or absence of RIP1 as revealed by immunohistology. Taken together, our study identified RIP1 as a crucial mediator of CD30-induced cell death that bears features of apoptosis as well as necroptosis. RIP1 expression in ALCL tumor cells might eligible for the therapeutic application of CD30 antibodies in combination with $\mathrm{NF} \kappa \mathrm{B} /$ proteasome inhibitors that should result in CD30-induced cell death.

Laboratory Investigation (2013) 93, 677-689; doi:10.1038/labinvest.2013.50; published online 1 April 2013

KEYWORDS: ALCL; apoptosis; $\mathrm{CD} 30 / \mathrm{CD} 30$ ligand; cell death; $\mathrm{NF} \kappa \mathrm{B}$; RIP1

CD30 belongs to the superfamily of tumor necrosis factor receptors (TNFR) and is predominantly expressed by tumor cells (Hodgkin and Reed Sternberg cells (HRS)) of classical Hodgkin lymphoma (cHL) and those of anaplastic large-cell lymphoma (ALCL). In normal tissue, CD30 expression is restricted to a subset of activated $\mathrm{T}$ and $\mathrm{B}$ cells. ${ }^{1}$ This selective and restricted expression strongly recommends $\mathrm{CD} 30$ as a therapeutic target. ${ }^{2}$ To this end, the knowledge of CD30driven effects and their underlying molecular mechanisms are mandatory. Comprehensive molecular analysis revealed that CD30 stimulation of ALCL cells mediates dramatic changes of mRNA and protein expression, resulting in cell cycle arrest without induction of cell death. ${ }^{3,4}$ Interestingly, a different pathway of CD30 signaling, ie, induction of massive cell death, becomes apparent under the condition of nuclear factor $\kappa \mathrm{B}(\mathrm{NF} \kappa \mathrm{B})$ inhibition by means of stable transfection with a dominant-negative $\mathrm{NF} \kappa \mathrm{B}$ inhibitor $(\mathrm{I} \kappa \mathrm{B} \alpha \Delta \mathrm{N})^{4}$ or proteasome inhibition. ${ }^{5}$ CD30-induced cell death of lymphocytes was further reported to occur under serum reduction, which was attributed to autocrine $\mathrm{TNF}^{6}{ }^{6}$ Of note, an involvement of autocrine TNF in terms of CD30-induced cell death under $\mathrm{NF} \kappa \mathrm{B}$-inhibited condition is not established.

Receptor-interacting protein 1 (RIP1) is a death homology domain (DD)-containing serine/threonine kinase. RIP1 participates in the signaling complexes that assemble upon activation of cell surface receptors, such as TLR3, TLR4, TNFR1, TRAILR, CD95/Fas, and CD40. ${ }^{7-9}$ Except TLR3, TLR4, and $\mathrm{CD} 40$, the numerated receptors belong to the subgroup of death receptors (DRs) carrying a DD. ${ }^{10-12}$ RIP1 is crucial for all three discriminable cell fates following TNFR1 stimulation: (i) NF $\kappa$ B-promoted survival, (ii) apoptosis, or (iii) programmed necrosis (necroptosis). ${ }^{13,14}$ Necroptosis refers to a regulated form of necrosis, ${ }^{15}$ and is biochemically defined as a form of presumably caspase-independent, RIP1-dependent

\footnotetext{
${ }^{1}$ Department of Experimental Haematology, Institute of Pathology, Charité-University Medicine Berlin, Campus Benjamin Franklin, Berlin, Germany and ${ }^{2}$ Pathodiagnostik, Berlin, Germany

Correspondence: Dr B Hirsch, PhD, Institute of Pathology, Charité-University Medicine Berlin, Campus Benjamin Franklin, D-12200 Berlin, Germany. E-mail: burkhard.hirsch@charite.de

${ }^{3}$ These authors contributed equally to this work.

Received 14 November 2012; revised 25 February 2013; accepted 3 March 2013
} 
cell death. ${ }^{16}$ The kinase activity of RIP1 is specifically important for the regulation of necroptosis and inhibited by Necrostatin-1 (Nec-1). ${ }^{17}$ Upon ligand binding, TNFR1 trimers undergo conformational changes that allow the cytoplasmic portions of receptors to recruit multiple proteins, including TNFR-associated death domain (TRADD), cellular inhibitor of apoptosis 1 (cIAP1), cIAP2, TNFR-associated factor 2 (TRAF2), TRAF5, and RIP1. This DD-associated, membrane -proximal structure has been named complex I. ${ }^{10}$ TRAF2 stabilizes cIAP1 and cIAP2 by preventing their polyubiquitylation. cIAP1/2 represent E3 ubiquitin ligases of RIP1. ${ }^{18,19}$ The site of ubiquitin addition determines the mode of RIP1 action. K63-linked ubiquitin chains are conjugated by IAPs and convey RIP1 to a scaffold molecule at the TNF receptor complex. Subsequently, transforming growth factor- $\beta$-activated kinase 1 (TAK1), TAK1-binding protein 2 (TAB2), and TAB3 are bound to this membrane associated complex (complex 1) that mediates $\mathrm{NF} \kappa \mathrm{B}$ and MAPK activation, followed by the expression of prosurvival genes. ${ }^{13,14}$ Further, it is well documented that RIP1 represents an integral component of the TNFR-uncoupled cytoplasmic apoptosis-inducing signaling complex. ${ }^{10,20}$

Although, CD30 does not belong to DD-carrying TNFRs, we and others demonstrated that CD30 stimulation induces cell death under $\mathrm{NF} \kappa \mathrm{B}$-inhibited condition ${ }^{4,5}$ that is inhibited by the pan-caspase inhibitor $\mathrm{z}$-VAD-fmk. ${ }^{4}$ Here, we uncovered the intracellular mechanisms of CD30-mediated cell death and identified RIP1 as the molecular link between CD30 and cell death induction. These findings might be valuable for $\mathrm{NF} \kappa \mathrm{B}$-associated $\mathrm{CD} 30$-targeted therapies.

\section{MATERIALS AND METHODS Cell Lines}

The cell lines DEL, SUPM2, SU-DHL1, SR 786, Karpas 299 (ALCL), and HeLa (carcinoma of the cervix uteri) were obtained from the German Resource Center for Biological Material (DSMZ, Braunschweig, Germany). The ALCL cell lines JB6, Mac-1, and FEPD were generous gifts from Dr M.E. Kadin (Harvard Medical School, Boston, MA, USA) and Dr K. Pulford (John Radcliff Hospital, University of Oxford, Oxford, UK), respectively. Comparative experiments were performed with the constitutively $\mathrm{NF} \kappa \mathrm{B}$-inhibited cell line $\mathrm{I} \kappa \mathrm{B} \alpha \Delta \mathrm{N}$-Karpas 299 (abbreviated $\Delta \mathrm{N}$-Karpas 299) that was stable transfected with the dominant-negative $\mathrm{NF} \kappa \mathrm{B}$ inhibitor $\mathrm{I} \kappa \mathrm{B} \alpha \Delta \mathrm{N} .{ }^{4}$ Cells were maintained in RPMI 1640 (PAA, Pasching, Austria) supplemented with $10 \%(\mathrm{v} / \mathrm{v})$ fetal bovine serum (PAA) and $4 \mathrm{mM}$ glutamine at $5 \%(\mathrm{v} / \mathrm{v}) \mathrm{CO}_{2}$ and $37^{\circ} \mathrm{C}$. The generation of constitutively NF $\kappa \mathrm{B}$-inhibited Karpas 299 cells by stable transfected $\mathrm{I} \kappa \mathrm{B} \alpha \Delta \mathrm{N}$ ( $\Delta \mathrm{N}$-Karpas 299) was described in detail previously. ${ }^{4}$

\section{CD30 Stimulation by Monoclonal Agonistic Antibody (mAb), Recombinant CD30 Ligand (CD30L) or Co-Culture with CD30L-Transfected HeLa Cells}

Exponentially growing CD30-positive cells (Karpas 299 or $\Delta \mathrm{N}$-Karpas 299) $\left(1.5 \times 10^{5} \mathrm{cells} / \mathrm{ml}\right)$ were CD30-stimulated by $\mathrm{mAB} \mathrm{Ki-1}(500 \mathrm{ng} / \mathrm{ml}$, produced in the Institute of Pathology, Charité-University Medicine Berlin, Campus Benjamin Franklin, Berlin, Germany), recombinant CD30L ( $100 \mathrm{ng} / \mathrm{ml}, \mathrm{R} \& \mathrm{D}$ Systems, Wiesbaden, Germany), and cocultured with CD30L- or mock-transfected HeLa cells for the indicated times, respectively. The effect of CD30 stimulation was compared and verified for the different CD30 stimulation systems by RQ-RT-PCR analysis of selected $\mathrm{NF} \kappa \mathrm{B}$-target genes (A20/TNFAIP3, cIAP2, and TRAF1) and by the analysis of cell death induction (Annexin V-FITC/PIstaining). The analysis of protein co-localization by confocal microscopy was performed with the newly established cellbound CD30L stimulation system. The CD30L cDNA was amplified from DG75, cloned into CloneAmp, subsequently transferred into pcDNA1.1 (Life Technologies, Invitrogen, Darmstadt, Germany), and sequenced (genetic analyzer, Life Technologies, Applied Biosystems, Darmstadt, Germany). HeLa cells were transfected with the CD30L expression plasmid by Turbofect (Fermentas/Thermo Scientific, St Leon-Rot, Germany). CD30L expression was verified by flow cytometry. Co-culture of CD30L-expressing HeLa cells and CD30-positive ALCL cells was started at $24 \mathrm{~h}$ after transfection for the indicated time. At the end of stimulation cells were fixed and stained as indicated. For further analysis CD30-positive Karpas 299 and $\Delta \mathrm{N}$-Karpas 299 cells were removed from HeLa cells by gentle pipetting, washed with PBS and collected by centrifugation at $200 \times g$ for 5 min.

\section{CD30 Stimulation of Proteasome Inhibited Cells}

We applied the proteasome inhibitor MG132 (Sigma-Aldrich, Taufkirchen, Germany) to systemic and cutaneous ALCL cell lines (DEL and Karpas 299: $0.2 \mu \mathrm{M}$, FEPD and Mac-1: $0.4 \mu \mathrm{M})$. One hour later, CD30 stimulation was initiated by $\mathrm{Ki}-1(500 \mathrm{ng} / \mathrm{ml})$ for a total of $16 \mathrm{~h}$. Flow cytometric analysis of cell death was performed following Annexin V-FITC/PIstaining.

\section{Cytokine (TNF) Analysis}

Cells were CD30-stimulated by Ki-1 for the indicated time. Secreted TNF was determined by flow cytometry using the Flow Cytomix Pro Kit (Bender Medsystems, Vienna, Austria). TNF (Sigma-Aldrich) and TNF mAb (D1B4, New England Biolabs, Frankfurt, Germany) were applied at 20 and $500 \mathrm{ng} / \mathrm{ml}$, respectively. A TNF doseresponse curve revealed that concentrations $>20 \mathrm{ng} / \mathrm{ml}$ did not further increase cell death of $\Delta \mathrm{N}$-Karpas 299 cells, determined by flow cytometric analysis of Annexin V/PI-stained cells (data not shown).

\section{Immunoblot Analyses, Immunohistochemistry and Reagents}

Cell extracts $(15 \mu \mathrm{g})$ were fractioned by SDS-PAGE (10 or 4-12\% NuPAGE gradient gels; Life Technologies, Invitrogen) 
and transferred to PVDF membranes (Serva, Heidelberg, Germany). Immunoblot was performed with the following antibodies: RIP1 (38/RIP, BD Biosciences, Heidelberg, Germany or Sigma-Aldrich; HPA015257), A20 and CD30 $\left(\right.$ Ber-A20 ${ }^{21}$ and Ber-H2, respectively; Institute of Pathology, Charité), Bcl-3 (SC-185), CD30 (SC1737), and I $\kappa \mathrm{B} \alpha$ (SC371) Santa Cruz, Heidelberg, Germany, full-length/cleaved PARP (MERCK, Calbiochem, Darmstadt Germany), cleaved PARP (Cell Signaling, Hamburg, Germany), cIAP1 (SigmaAldrich), cIAP2 (ab32059, Abcam, Cambridge, UK), and the control mAb $\beta$-actin (ab6276, Abcam Cambridge, UK). HRP-conjugated secondary antibodies were detected by chemiluminescence (Amersham Biosciences, Freiburg, Germany). Immunohistochemistry was carried out as published $^{22}$ with the RIP1 (HPA015257, Sigma-Aldrich) antibody. A strong and reproducible immunohistological staining with the RIP1 $\mathrm{mAb}$ of $>80 \%$ of neoplastic cells was scored positive. Tumor cells were scored RIP1-negative if no staining of the neoplastic cells was detected but a few small bystander cells showed at least weak RIP1 expression. The utilization of patients' samples for immunohistology was approved by the ethics committee of the Charité (EA4/010/ 09) and conducted accordingly. The Smac mimetic (IAPantagonist) BV6 was kindly provided by Dr Vucic (Genentech, USA).

\section{Analysis of CD30-Stimulated Cells by Confocal Microscopy}

CD30-positive ALCL cells were co-cultured in chamber slides for the indicated times with CD30L-/mock-transfected cells (Nunc, Thermo Scientific, Langenselbold, Germany). To perform RIP1/CD30/nuclei triple-fluorescence staining, cells were washed with PBS, air-dried, and acetone-fixed. Fixed cells were blocked with PBS containing 5\% (v/v) FCS (PAA) for $1 \mathrm{~h}$. Staining was carried out under humidified atmosphere with RIP1 (Sigma-Aldrich) and CD30 (Ber-H2) antibodies, detected by Alexa fluor 488- and Alexa fluor 555-conjugated antibodies (Dianova, Hamburg, Germany), respectively. Nuclei were depicted by TOTO-3 (Molecular Probes, Paisley, UK). Stained cells were examined with a confocal microscope (TCS NT, Leica Microsystems, Wetzlar, Germany) and analyzed by Leica software LCS Lite.

\section{Flow Cytometry}

Staining of dead/apoptotic cells was performed with the Annexin V-FITC Apoptosis Detection Kit I (BD Biosciences Pharmingen, Heidelberg, Germany) according to manufacturers' instructions. Labeled cells were analyzed by a FACSort or Accuri C6 (Becton Dickinson, Heidelberg, Germany). CD30L was stained by goat-antibody (Santa Cruz), detected by anti-goat-biotin and PE-conjugated Streptavidin (DakoCytomation, Hamburg, Germany).

\section{RNA Extraction and Reverse Transcription-Relative Quantitative-Real Time-PCR (RT-RQ-PCR)}

Total RNA of RIP1 siRNA-treated/control siRNA-treated and control/CD30-stimulated ALCL cells was extracted, according to standard protocols (Qiagen, Hilden, Germany). RT-RQPCR was carried out as published ${ }^{22}$ with the following pairs of oligonucleotides (forward/reverse): A20: 5'-AGCTTTCTC TCATGGATGTAAAATGTG- $3^{\prime} / 5^{\prime}$-GCATAAAGGCTGGGTG TTCAC-3', cIAP2: 5'-GGACTCAGGTGTTGGGAATCTG-3' 5'-CCTTTAATTCTTATCAAGTACTCACACCTT-3', RIP1: 5' GAGGTTGGTGGGACGAGTTC-3'/5'-TGGTACTTGGAAGC TGGCTCTT-3', TRAF1: 5' -TGCGGCTGTACCTGAATGG-3' $/$ 5'-ATACTCCCCTCTCATGATCACGAT-3', hypoxanthine ribosyl transferase (HPRT): 5'-GAGTCCTATTGACATCGCCAGT A-3'/5'-CTAAGCAGATGGCCACAGAACTAG-3'. HPRT served as endogenous control. HPRT-normalized gene expression was calculated by the $2^{-{ }^{-\Delta}} \mathrm{CT}$ method. ${ }^{23}$

\section{RIP1 Inhibition Experiments}

Downregulation of RIP1 in Karpas 299 and $\Delta$ N-Karpas 299 cells was performed by RIP1 siRNA (ON TARGET plus SMART pool, Thermo Scientific/Dharmacon, Erembodegem, Belgium) transfection (Amaxa, Köln, Germany), consisting of four different RIP1 siRNAs. Mock-transfections were performed by control siRNA (non-targeting pool, Thermo Scientific/ Dharmacon). In addition, RIP1 was inhibited pharmacologically by Nec-1 (Biomol, Hamburg, Germany) or Geldanamycin (GA, Sigma-Aldrich). Subsequently, cells were CD30-stimulated or control-treated for the indicated times. Downregulation of RIP1 was monitored by immunoblot analysis.

\section{Processing of Microarray Data}

Gene-expression data were obtained from three publicly available data bases (GSE6338, GSE14879, and GSE19069 at the National Center for Biotechnology Information Gene Expression Omnibus repository http://www.ncbi.nlm. nih.gov/geo/ ). ${ }^{24-26}$ Expression values were extracted from Affymetrix chip definition files and manufacturer's annotations for HG-U133 Plus 2.0 arrays. CEL-files were imported into Partek Genomic Suite Software (Version 6.4; Partek, St Louis, Missouri, USA) and processed by the implemented robust multiarray (RMA) workflow (median polish probe set summarization, RMA background correction and quantile normalization).

\section{Statistical Analysis}

Data were statistically analyzed using the Student $t$-test (unpaired, two-tailed, 95\% confidence interval).

\section{RESULTS \\ CD30 Stimulation Induced Cell Death in NF $\kappa$ B Pathway Inhibited ALCL Cells}

The experimental approach of this study was based on the different CD30-signaling effects leading to massive induction of cell death in $\Delta \mathrm{N}$-Karpas 299 cells $(\mathrm{NF} \kappa \mathrm{B}$-inhibited I $\kappa \mathrm{B} \alpha \Delta \mathrm{N}$-Karpas 299 cells), whereas native Karpas 299 cells 
remained alive upon $\mathrm{CD} 30$ stimulation (Figure 1a). In order to determine whether $\mathrm{CD} 30$-induced cell death also takes place in pharmacologically NF $\kappa$ B-inhibited ALCL cells, we applied the proteasome inhibitor MG132 to different systemic and cutaneous ALCL cell lines and initiated CD30 stimulation after $1 \mathrm{~h}$ for a period of $16 \mathrm{~h}$. CD30 stimulation of MG132-treated ALCL cell lines (Karpas 299 and DEL $0.2 \mu \mathrm{M}$, FEPD and Mac-1 $0.4 \mu \mathrm{M})$ induced massive cell death as determined by flow cytometry (Figure 1b). In detail, cell death of MG132-treated cells was increased by CD30 stimulation in NPM-ALK-positive
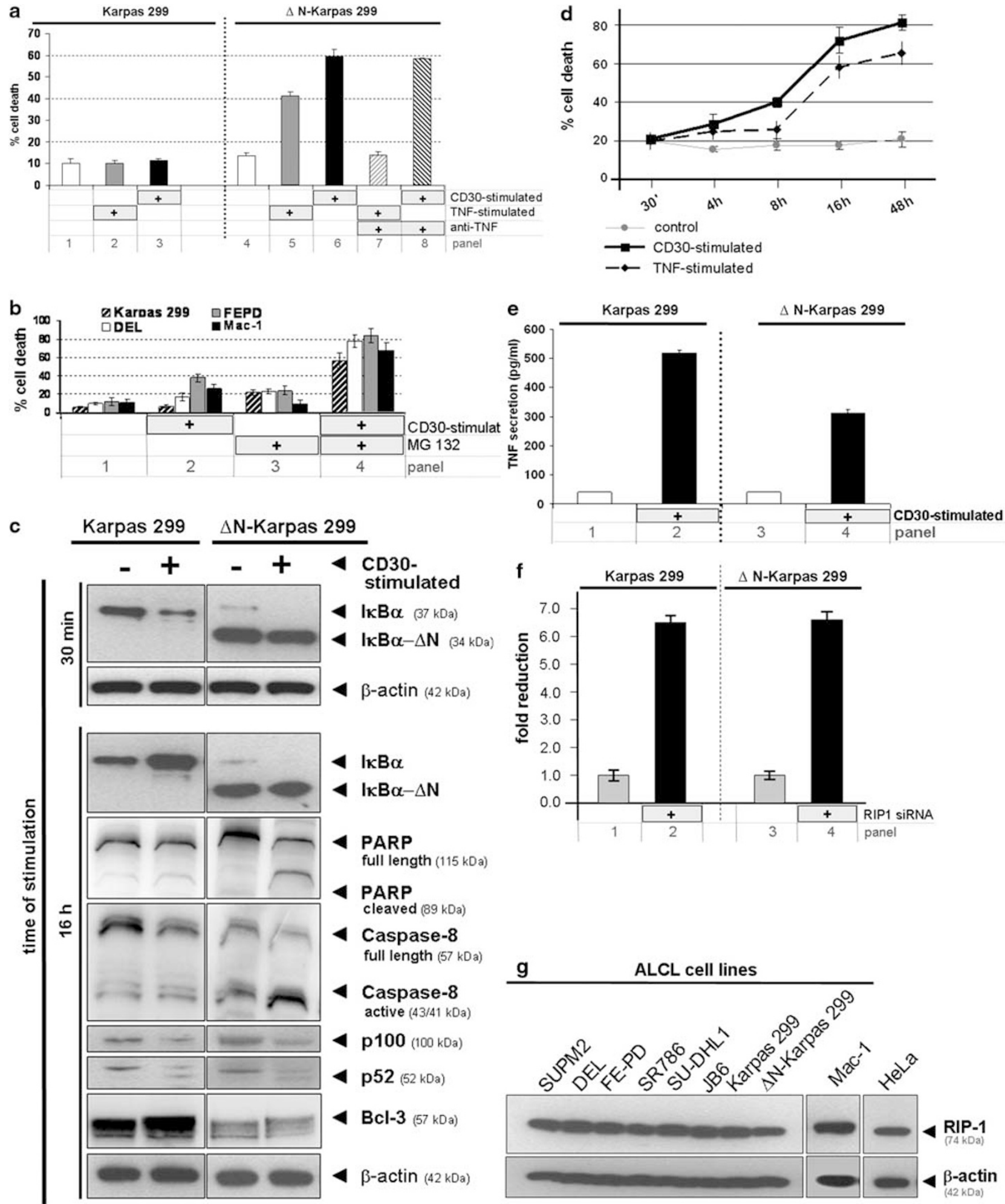

CD30stimulated

f

$\mathbf{I K B} \boldsymbol{\alpha}(37 \mathrm{kDa})$

IkB $\alpha-\Delta N_{(34} \mathrm{kDa}$

$\beta$-actin (42 kDa)

$\mid \mathrm{k} B \alpha$

IkB $\alpha-\Delta N$

PARP

full length $(115 \mathrm{kDa})$

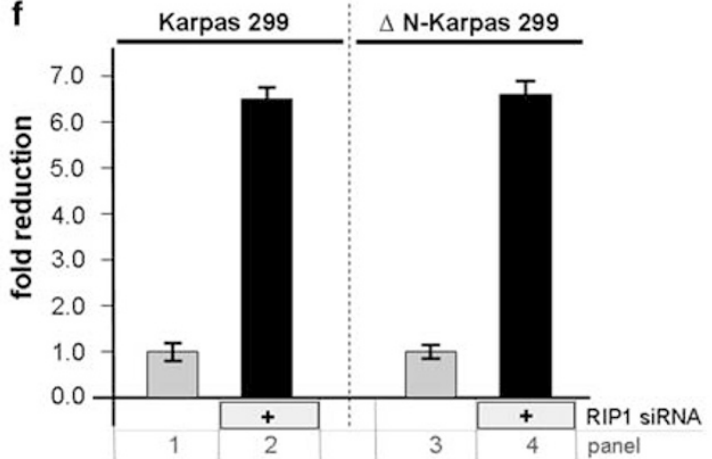

PARP

cleaved (89 kDa)

4 Caspase-8

full length (57 kDa)

Caspase-8

active (43/41 kDa)

p100 (100 kDa)

p52 (52 kDa)

$\mathrm{Bcl}-3$ (57 kDa)

$\beta$-actin (42 kDa)

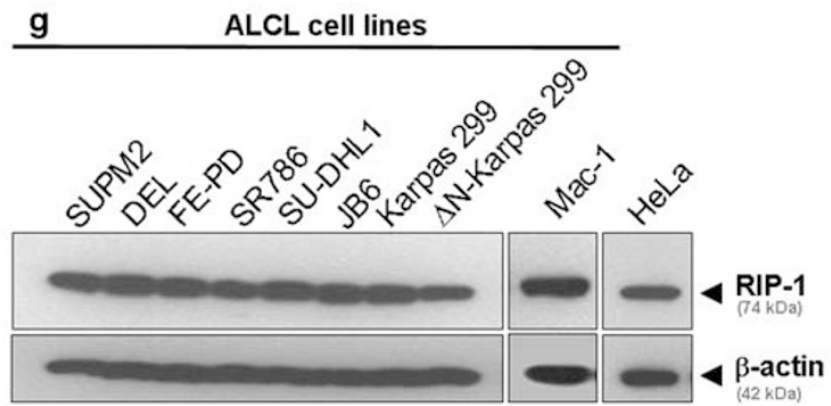


Karpas 299 (35\%) and DEL (55\%) as well as NPM-ALKnegative FEPD (60\%) and Mac-1 (59\%), as compared with control-treated cells.

CD30 stimulation of CD30-positive Karpas 299 cells led to a short-term degradation of $\mathrm{I} \kappa \mathrm{B} \alpha$ at $30 \mathrm{~min}$ (Figure 1c) and subsequent canonical $\mathrm{NF} \kappa \mathrm{B}$ activation. $\mathrm{I} \kappa \mathrm{B} \alpha$ expression was more than re-established after $16 \mathrm{~h}$ CD30 stimulation (Figure 1c, middle panel). In $\Delta \mathrm{N}$-Karpas 299 cells, only minor expression of wild-type $\mathrm{I} \kappa \mathrm{B} \alpha(37 \mathrm{kDa})$ was still detectable, which was completely degraded following $30 \mathrm{~min}$ of CD30 stimulation. CD30 stimulation of $\Delta \mathrm{N}$-Karpas 299 cells for $16 \mathrm{~h}$ did not lead to reestablishment of $\mathrm{I} \kappa \mathrm{B} \alpha$ expression. The overexpressed $\mathrm{I} \kappa \mathrm{B} \alpha \Delta \mathrm{N}$ $(34 \mathrm{kDa})$ was not affected by CD30 stimulation (Figure 1c). Poly (ADP-ribose) polymerase (PARP) represents one of the main cleavage targets of caspase- 3 . We revealed an increase of cleaved PARP upon $16 \mathrm{~h}$ CD30 stimulation of $\Delta \mathrm{N}$-Karpas 299 cells (Figure 1c, middle panel), where full-length PARP $(115 \mathrm{kDa})$ decreased in consequence. In line with this, we demonstrated the CD30-induced activation of caspase-8 $(43 / 41 \mathrm{kDa})$ of $\Delta \mathrm{N}$-Karpas 299 cells (Figure 1c, lower panel). In the opposite, neither induction of cell death (Figure 1a) nor cleavage of PARP or caspase-8 activation occurred in native Karpas 299 following CD30 stimulation (Figure 1c).

In addition to canonical $\mathrm{NF} \kappa \mathrm{B}$-pathway, we investigated $\mathrm{CD} 30$-mediated non-canonical NF $\kappa \mathrm{B}$-pathway activation. As depicted in Figure 1c, CD30 stimulation induced p100/p52 processing as well as Bcl-3 activation in native Karpas 299 and $\Delta \mathrm{N}$-Karpas 299 cells. Constitutive and CD30-mediated $\mathrm{Bcl}-3$ expression was less pronounced in $\Delta \mathrm{N}$-Karpas 299 cells as compared with native Karpas 299 cells.

\section{CD30-Induced Cell Death of $\Delta \mathrm{N}$-Karpas 299 Cells was not Mediated by Autocrine TNF}

Next we asked whether CD30-induced TNF secretion contributed to CD30-mediated cell death of NF $\kappa$ B-inhibited cells as published for cells under serum starvation. ${ }^{6}$ TNF was secreted constitutively on the same low level by Karpas 299 cells and $\Delta \mathrm{N}$-Karpas 299 cells $(39.8 \pm 2.1$ and $40.2 \pm 1.4 \mathrm{pg} /$ $\mathrm{ml}$, respectively). CD30 stimulation for $16 \mathrm{~h}$ induced TNF secretion of native Karpas 299 up to $518.8 \pm 8.4 \mathrm{pg} / \mathrm{ml}$ but only up to $312 \pm 10.6 \mathrm{pg} / \mathrm{ml}$ of $\Delta \mathrm{N}$-Karpas 299 cells (Figure 1e). Noteworthy, only $\Delta \mathrm{N}$-Karpas 299 cells showed CD30-induced cell death. The lower TNF secretion of $\Delta \mathrm{N}$-Karpas 299 cells was not attributed to lower cell numbers as a consequence of CD30-induced cell death. Even at shorttime CD30 stimulation $(5 \mathrm{~h})$, where no cell death was measured by flow cytometry, $\Delta \mathrm{N}$-Karpas 299 cells secreted lower amounts of TNF (data not shown). We demonstrated that native Karpas 299 cells were neither CD30- nor TNF-apoptosis sensitive at normal serum concentration. In contrast, $\Delta \mathrm{N}$-Karpas 299 cells were sensitive to CD30- and TNFmediated cell death. A saturating dose of exogenous TNF $(20 \mathrm{ng} / \mathrm{ml})$ induced $41 \pm 2.1 \%$ apoptosis (Figure 1a). The kinetic (30 min, 4, 8, 16, and $48 \mathrm{~h}$ ) of CD30- and TNF-induced cell death of $\mathrm{NF} \kappa \mathrm{B}$-inhibited $\Delta \mathrm{N}$-Karpas 299 cells was analyzed by flow cytometry (Figure 1d).

To elucidate whether autocrine TNF was involved in CD30-induced cell death of $\Delta \mathrm{N}$-Karpas 299 cells, we preincubated cells with a TNF-neutralizing monoclonal antibody (D1B4) at $500 \mathrm{ng} / \mathrm{ml}$ for $0.5 \mathrm{~h}$ and performed CD30 or TNFR1 stimulation for $16 \mathrm{~h}$, subsequently. D1B4 completely blocked TNF-induced cell death of $\Delta \mathrm{N}-\mathrm{K} 299$ cells (Figure 1a, panel 7). In contrast, CD30-induced cell death was not affected by TNF-neutralization (Figure 1a, panel 8). These findings clearly indicated that autocrine TNF was not involved in CD30-induced cell death of $\Delta \mathrm{N}$-Karpas 299 cells.

\section{CD30-Induced Cell Death was Mediated by RIP1 in $\Delta \mathbf{N}$-Karpas 299 Cells}

The consistent expression of RIP1 protein of all untreated ALCL cell lines and HeLa cells that have been investigated in this study is shown in Figure $1 \mathrm{~g}$ by immunoblot. As RIP1 represents an important component of DD-carrying TNFRsignaling complexes, we reasoned whether it also participates

Figure 1 Analysis of CD30- and TNF-induced cell death of canonical NF $\kappa$ B-inhibited ALCL cell lines, effects of proteasome inhibition, kinetic of CD30- and TNF-induced cell death, CD30-mediated TNF secretion, RIP1 expression, and RIP1 siRNA-mediated inhibition of CD30-induced cell death of ALCL cell lines. (a) Flow cytometric analyses of cell death (Annexin V-FITC/PI stain) of native Karpas 299 and $\Delta \mathrm{N}-\mathrm{Karpas} 299$ cells after $16 \mathrm{~h}$ control-, CD30- (Ki-1), or TNF stimulation with and without TNF monoclonal antibody (D4B1)-mediated TNF-neutralization. (b) Flow cytometric analyses of CD30-induced cell death of NPM-ALK-positive ALCL cell lines Karpas 299 and DEL as well as NPM-ALK-negative ALCL cell lines FEPD and Mac-1 that were pretreated for $1 \mathrm{~h}$ with the proteasome inhibitor MG132. CD30 stimulation was performed with the agonistic CD30 antibody Ki-1 during the last 15 h. (c) Native Karpas 299 (left panel) and constitutively NF $\kappa$ B-inhibited cells ( $\Delta \mathrm{N}$-Karpas 299, right panel) were CD30/mock-stimulated and analyzed by immunoblotting. Activation of the canonical NF $\kappa$ B pathway was analyzed by $\mid \kappa B \alpha$-degradation after 30 min of $C D 30$ stimulation. $\mathrm{NF} \kappa \mathrm{B}$-mediated upregulation of $\mathrm{I} \kappa \mathrm{B} \alpha$, full-length/cleaved PARP, and inactive/active caspase- 8 expression is analyzed at $16 \mathrm{~h}$ of $\mathrm{CD} 30$ stimulation. CD30-mediated noncanonical NF $\kappa$ B regulation is indicated by p100/p52 processing as well as CD30-induced Bcl-3 activation in native Karpas 299 and $\Delta$ N-Karpas 299 cells. Experiments were repeated at least two times with similar results. (d) Kinetic of CD30- and TNF-induced cell death of $\Delta \mathrm{N}-\mathrm{Karpas} 299$ cells is shown. (e) TNF secretion of $16 \mathrm{~h}$ CD30-stimulated/control-treated native Karpas 299 and $\Delta \mathrm{N}$-Karpas 299 cells as determined by flow cytometry. (f) RT-RQ-PCR analyses of non-targeting control siRNA-transfected and RIP1 siRNA (pool of 4)-transfected native Karpas 299 (left panel) and $\Delta$ N-Karpas 299 cells (right panel). RIP1 siRNA-mediated a 6.5 -fold $(R Q=0.15)$ or 6.6 -fold $(R Q=0.15)$ reduction of RIP1 mRNA, respectively. The diagram shows HPRT-normalized relative mRNA data of expression. (g) Western blot analyses of RIP1 expression of ALK-positive (SUPM2, DEL, SR 786, SU-DHL1, JB6, Karpas 299, $\Delta \mathrm{N}$-Karpas 299) and ALK-negative (FEPD, Mac-1) ALCL lymphoma cell lines and HeLa cells. Expression of $\beta$-actin served as loading control. Mean \pm s.d. of three experiments is shown for $\mathbf{a}, \mathbf{b}, \mathbf{d}, \mathbf{e}$, and $\mathbf{f}$. 
a

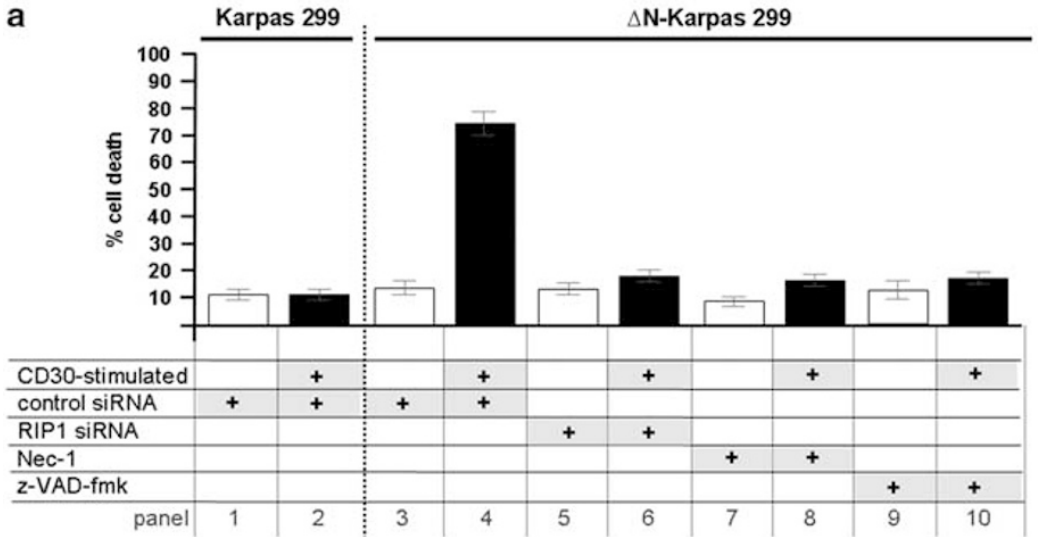

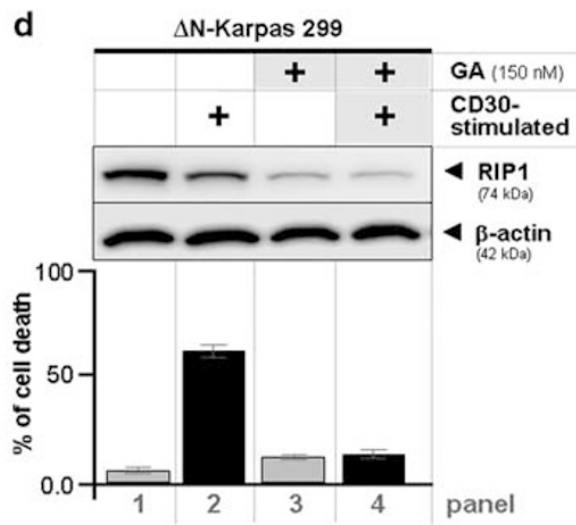

$\Delta \mathrm{N}$-Karpas 299

Karpas 299

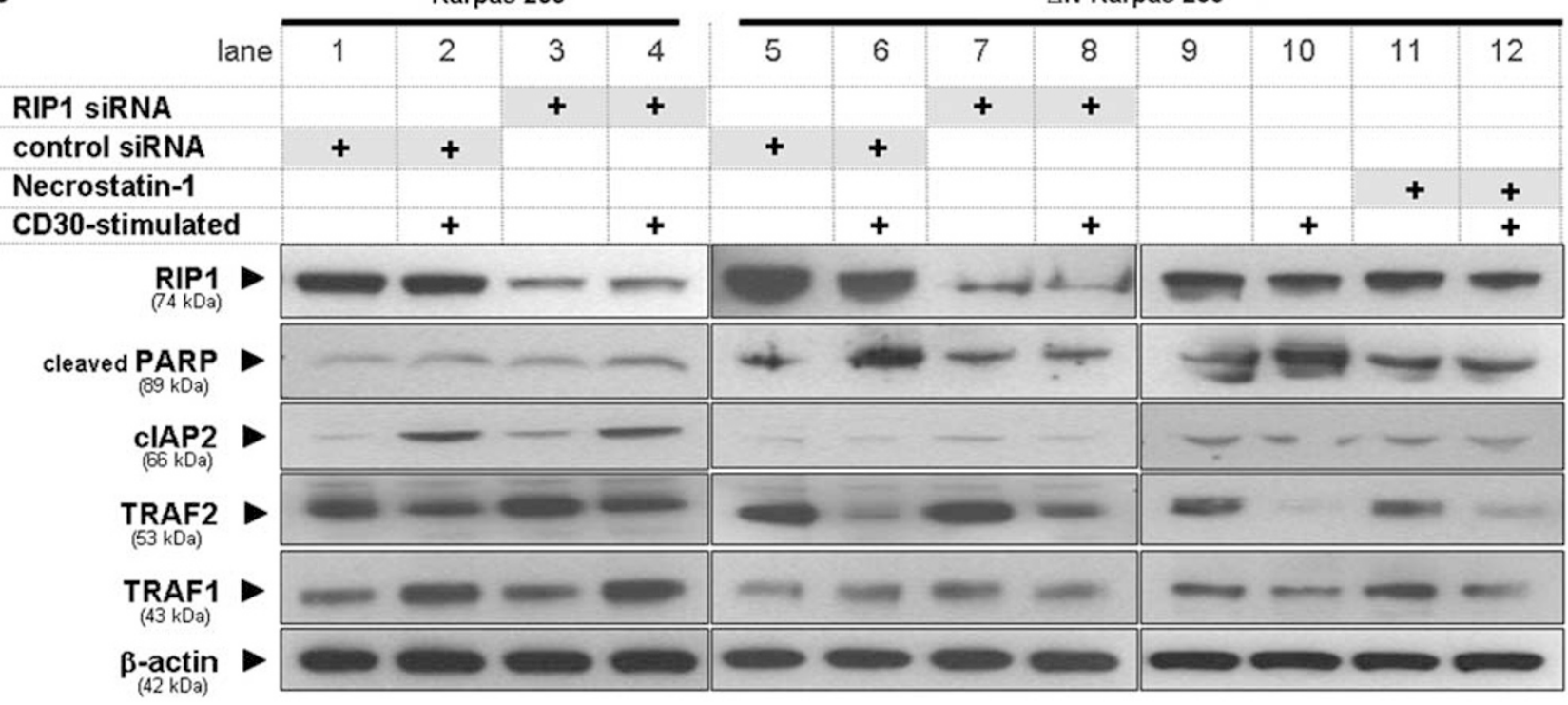

c

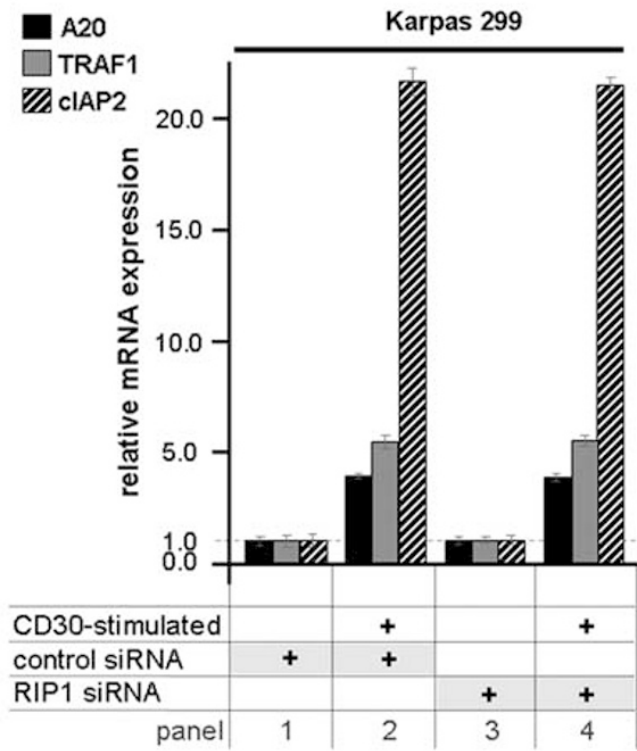

e

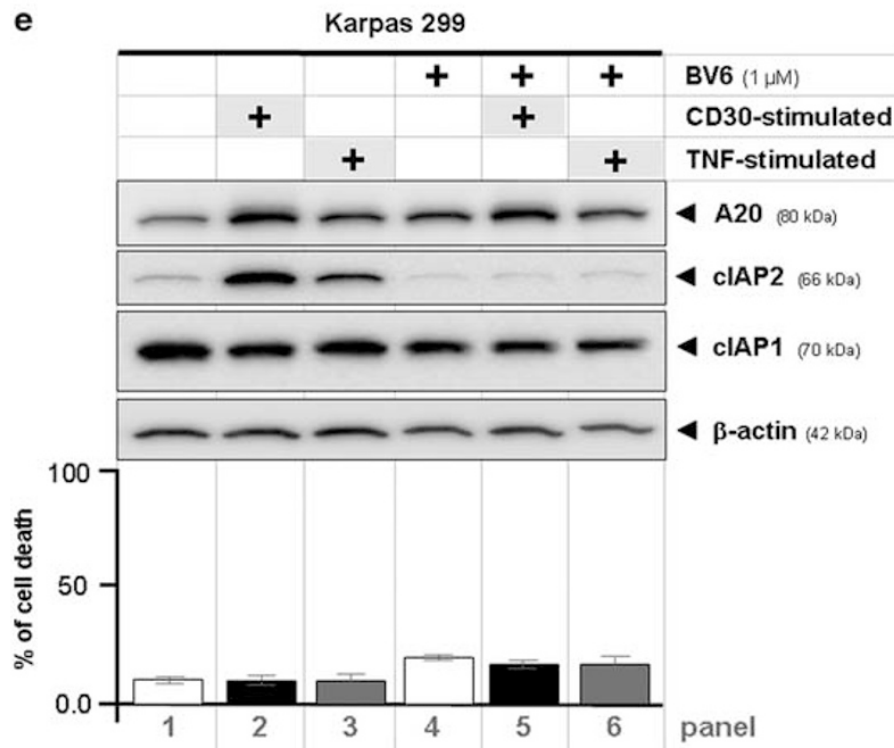


in CD30 signaling. To prove this, we performed RIP1 downregulation by RIP1 siRNA (a pool of four RIP1 siRNAs). As revealed by RT-RQ-PCR analysis, RIP1 siRNA transfection diminished RIP1 mRNA 6.5- and 6.6-fold $(\mathrm{RQ}=0.15)$ in Karpas 299 and $\Delta \mathrm{N}$-Karpas 299 cells, respectively (Figure 1f). These results were confirmed by immunoblot and analyzed in the context of additional relevant proteins at a later stage of the experiments (Figure 2c).

However, and most strikingly, CD30-induced cell death of $\Delta \mathrm{N}$-Karpas 299 cells was prevented almost completely by RIP1 siRNA-mediated RIP1 inhibition (Figure 2a, 6th panel), which was accompanied by reduced PARP cleavage (Figure 2b, compare lane $6+8$ ).

RIP1 inhibition of native Karpas 299 did not change CD30 signaling. We determined the expression of known CD30 target genes by RT-RQ-PCR analysis of RIP1/control siRNAtreated, $16 \mathrm{~h}$ CD30-stimulated Karpas 299 cells. RIP1 downregulation did not affect CD30-induced expression of A20, cIAP2 or TRAF1 (Figure 2c). Noteworthy, RIP1associated effects became apparent only under $\mathrm{NF} \kappa \mathrm{B}$ inhibited condition following CD30 stimulation.

\section{Nec-1 and GA Inhibited CD30-Induced Cell Death in $\Delta \mathrm{N}$-Karpas 299 Cells}

To confirm our RIP1 siRNA results by means of pharmacological approaches, we applied the allosteric RIP1 kinase inhibitor Nec- $1^{17}$ to $\Delta \mathrm{N}$-Karpas 299 cells (Figure $2 \mathrm{a}$ and b). As revealed by flow cytometry, the extent of Nec-1-mediated inhibition $(20 \mu \mathrm{M})$ of CD30-induced cell death was comparable to our RIP1 siRNA results (Figure 2a). Owing to Nec1-mediated RIP1 kinase inhibition, RIP1 expression itself was not influenced by Nec-1 (Figure 2b, lane $11+12$ ). Nec-1mediated inhibition of CD30-induced cell death was accompanied by reduced PARP cleavage (Figure 2b, 2nd row, compare lane $10+12$ ). To add additional proof-of-concept, we inhibited RIP1 in $\Delta \mathrm{N}$-Karpas 299 cells by the anti-tumor drug GA (150 nM: preincubation for $16 \mathrm{~h}$ ) and performed CD30 stimulation for $16 \mathrm{~h}$ subsequently. Western blot analysis revealed that GA treatment decreased RIP1 expression dramatically (Figure 2d, upper panel) and prevented CD30-induced cell death as measured by flow cytometry (Figure 2d, lower panel). GA treatment raised merely a slightly increased constitutive cell death (Figure 2d, lower part). A simplified model of CD30 signal transduction in native and NF $\kappa \mathrm{B}$-inhibited ALCL cells is given in Figure 3. The two kinds of CD30induced cell death, ie, necroptosis and apoptosis are indicated.

\section{The CD30 Targets CIAP2 and TRAF1 were not Affected by RIP1 Inhibition}

In native Karpas 299 cells, CD30-induced upregulation of known CD30 target proteins like CIAP2 and TRAF1 was not affected by RIP1 siRNA-mediated RIP1 inhibition (Figure 2b, lane 1-4). In $\Delta \mathrm{N}$-Karpas 299 cells, the expression of cIAP2 and TRAF1 is not inducible by CD30 stimulation and was also not altered by RIP1 inhibition (Figure 2c, lane 5-8). Moreover, TRAF2 degradation was not influenced by Nec-1 or RIP1 siRNA in $\Delta \mathrm{N}$-Karpas 299 cells or RIP1 siRNA treatment of Karpas 299 cells (Figure $2 \mathrm{~b}$, lane $11+12,7+8$ or lane $3+4$, respectively); also CD30-mediated TRAF2 degradation was more pronounced in $\Delta \mathrm{N}$-Karpas 299 cells as compared with native Karpas 299 (Figure $2 \mathrm{~b}$, lane $5+6 v s 1+2$ ). These data indicate that RIP1 inhibition of ALCL cells does not affect $\mathrm{NF} \kappa \mathrm{B}$-mediated CD30-signaling events but rather CD30-induced cell death.

\section{Low clAP2 Expression was not Responsible for CD30- or TNF-Induced Cell Death in $\triangle \mathrm{N}$-Karpas 299 Cells}

Previously, we and others demonstrated that cIAP2 expression was significantly induced by CD30 stimulation of different ALCL cell lines, including Karpas 299. ${ }^{4,27}$ Here, we showed that CD30 stimulation of $\Delta \mathrm{N}$-Karpas 299 cells did not increase cIAP2 expression (Figure 2b). Based on the fact that cIAP2 represents an ubiquitin ligase, mediating K63-linked RIP1 ubiquitination, ${ }^{19}$ we wondered whether consistently low cIAP2 expression as revealed in $\Delta \mathrm{N}$-Karpas 299 cells might be involved in the CD30- and TNF-mediated cell death. To address this issue, we pre-incubated Karpas 299 cells with $1 \mu \mathrm{M}$ Smac mimetic (BV6; IAP inhibitor) for $2 \mathrm{~h}$ and performed a CD30 or TNF stimulation for $16 \mathrm{~h}$, subsequently. BV6 almost completely abolished cIAP2 expression and to a lesser extent cIAP1 expression as demonstrated by immunoblot (Figure 2e) and abrogated CD30- and TNF-mediated upregulation of cIAP2 as

Figure 2 CD30-induced cell death is inhibited by RIP1 siRNA, RIP1 kinase inhibitor Necrostatin-1 (Nec-1), Geldanamycin (GA), and pan-caspase inhibitor z-VAD-fmk in $\Delta \mathrm{N}$-Karpas 299 cells, whereas BV6-mediated IAP-inhibition did not render native Karpas 299 cells to induce cell death following CD30 or TNF stimulation. (a) Results of flow cytometric analyses of cell death (Annexin V-FITC/PI) of $16 \mathrm{~h}$ unstimulated/CD30-stimulated native Karpas 299 and $\triangle \mathrm{N}$-Karpas 299 cells are depicted. Additionally, the latter cells were control/RIP1 siRNA-transfected, Nec-1-treated, or z-VAD-fmk-treated. (b) Immunoblot analyses of the cells presented in A. Native Karpas 299 cells were transfected with non-targeting (control) siRNA and RIP1 siRNA (SMART pool, consisting of four different siRNAs) (lane 1-4). $\Delta \mathrm{N}$-Karpas 299 cells were transfected with control siRNA (lane $5+6$ ) or RIP1 siRNA (lane $7+8$ ), mediumtreated (lane $9+10)$, or Nec-1-treated $(20 \mu \mathrm{M}$, lane $11+12)$ and subsequently control/CD30-stimulated for $16 \mathrm{~h}$. RIP1, cleaved PARP, cIAP2, TRAF2, and TRAF1 antibodies were used for analyses. (c) Native Karpas 299 cells were non-targeting control siRNA/RIP1 siRNA-transfected and $16 \mathrm{~h}$ control/CD30stimulated. The expression of A20, ClAP2, and TRAF1 mRNA was analyzed by RT-RQ-PCR. HPRT-normalized data are shown. (d) Immunoblot analyses of RIP1 expression (upper panel) and flow cytometric analyses of cell death (lower panel) of $\Delta \mathrm{N}$-Karpas 299 cells, pretreated with Geldanamycin (150 nM) for $16 \mathrm{~h}$, followed by $16 \mathrm{~h}$ control/CD30 stimulation. (e) Immunoblot analyses of A20, cIAP1, and cIAP2 (upper part) and flow cytometric cell death evaluation (lower part) of Karpas 299 cells, pretreated with IAP-antagonist BV6 $(1 \mu \mathrm{M})$ for $2 \mathrm{~h}$ and subsequent $16 \mathrm{~h}$ control/CD30-/TNF stimulation. One representative analysis out of three independent experiments is shown. Expression of $\beta$-actin served as loading control in $\mathbf{b}, \mathbf{d}$, and $\mathbf{e}$. Data of $\mathbf{a}$, $\mathbf{c}$, $\mathbf{d}$, and $\mathbf{e}$ are presented as mean \pm s.d. of three experiments. 
well as CD30-mediated cIAP1 inhibition ${ }^{28}$ (Figure 2e). Despite very strong cIAP2 inhibition, CD30 stimulation of these IAPinhibited Karpas 299 cells did not induce cell death. Only spontaneous basal cell death rates were slightly increased by BV6 (Figure 2e, lower panel). Importantly, BV6-mediated cIAP inhibition did not affect CD30-induced gene expression as demonstrated exemplarily by the upregulation of A20, which was reported to function as a regulator of $\mathrm{NF} \kappa \mathrm{B}$ by means of deubiquitinating RIP1 following TNF stimulation ${ }^{20}$ (Figure 2e).

\section{CD30 Stimulation of $\Delta \mathrm{N}$-Karpas 299 Cells in a Cell-Based CD30L Expression System Induced Accumulation of RIP1 at the Cytoplasma Membrane and Co-Localization with CD30}

Our data revealed that $\mathrm{CD} 30$-induced cell death of $\mathrm{NF} \kappa \mathrm{B}$ inhibited cells is mediated by RIP1. In order to study cellular localization of RIP1 in the context of CD30 signaling in individual cells, we established a cell-cell contact-based CD30 stimulation system that is closer to the physiological situation. To this end, HeLa cells were transfected with CD30 ligand (CD30L; efficiency 35\%; Figure 4a) that was expressed at the cell surface. As demonstrated by co-culture of $\Delta \mathrm{N}$-Karpas 299 cells $(16 \mathrm{~h})$, the CD30L-expressing HeLa cells were able to induce apoptosis to an extent (50\%) very similar to the treatment with the recombinant CD30L $(100 \mathrm{ng} / \mathrm{ml})$ or agonistic monoclonal CD30-antibody $\mathrm{Ki}-1 \quad(500 \mathrm{ng} / \mathrm{ml})$ (Figure 4c). ${ }^{4}$ Mock-transfected HeLa cells did not affect viability of co-cultured lymphocytes as revealed by flow cytometry and microscopic analysis (Figure 4b). Neither
CD30L- nor mock-transfected HeLa cells induced cell death of native Karpas 299, DEL or Mac-1 cells (data not shown). Similarly, CD30 target genes were only upregulated by coculture of CD30L-expressing HeLa cells and native Karpas 299 cells, whereas mock transfected were not effective (Figure 4d).

Co-culture of native Karpas 299 cells as well as $\Delta \mathrm{N}$-Karpas 299 cells with CD30L-expressing HeLa cells induced an almost complete attachment of CD30-positive cells to CD30L-expressing cells at $2 \mathrm{~h}$. There was almost no attachment with mock-transfected cells. Confocal analysis of CD30-stimulated $\Delta \mathrm{N}$-Karpas 299 cells, immunostained for CD30 and RIP1, revealed massive accumulation of RIP1 at the cytoplasma membrane and a co-localization of RIP1 and CD30 (Figure 5b, middle and lower panels). In contrast, these effects did not take place in native Karpas 299 cells (Figure 5a) or in $\Delta \mathrm{N}$-Karpas 299 cells co-cultured with mock-transfected HeLa cells (Figure 5b, upper panel). These data demonstrate that CD30 and RIP1 represent an 'intimate couple' under CD30 stimulation of $\mathrm{NF} \kappa \mathrm{B}$-deficient cells.

\section{RIP1 Expression of Primary Cases of Systemic ALCL}

We also investigated RIP1 expression of systemic ALCL cases in vivo by immunohistology. Interestingly, 10/12 ALKpositive cases and 5/9 ALK-negative ALCL cases showed cytoplasmic RIP1 expression (Figure 5c). As our in vitro data uncovered that RIP1 expression represents the prerequisite for $\mathrm{CD} 30$-induced cell death to occur in $\mathrm{NF} \kappa \mathrm{B}$-inhibited ALCL cells, the detection of RIP1-positivity might be of
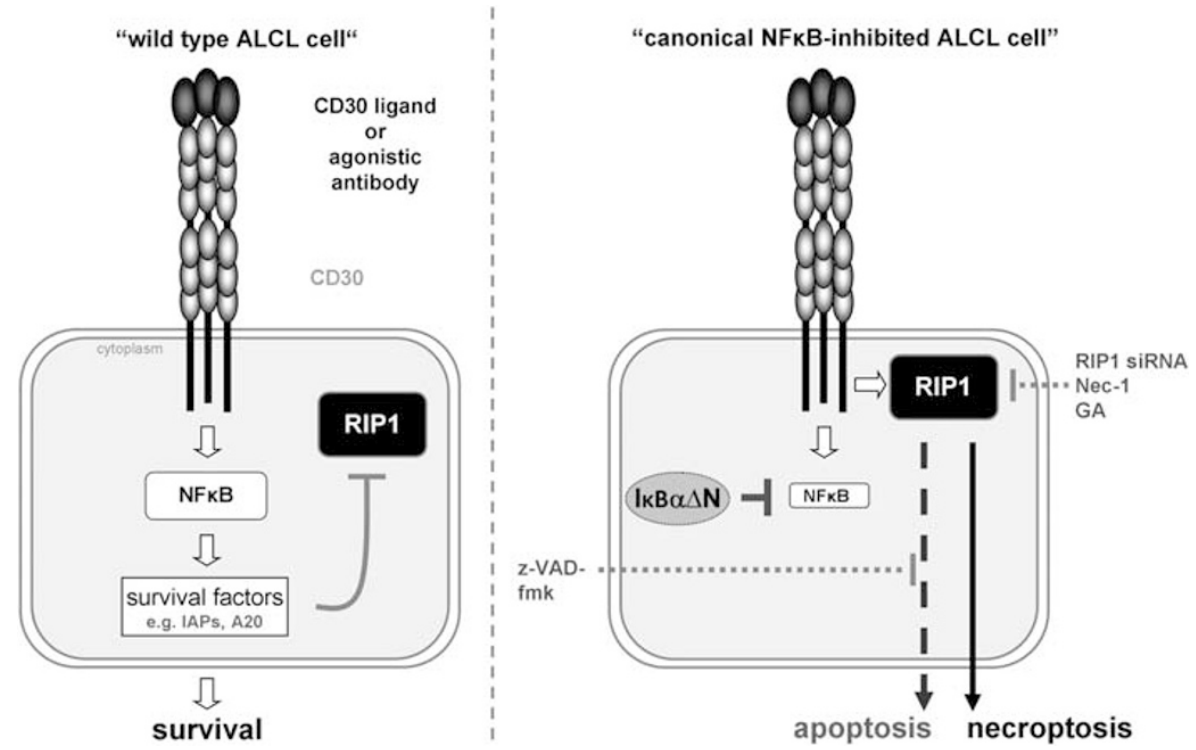

Figure 3 Simplified proposed model of CD30-induced cell death in ALCL cells. CD30 stimulation of wild-type ALCL cells leads to NF $\kappa$ B-mediated gene expression and subsequent survival (left panel). In the opposite, CD30 stimulation of NF $\kappa$ B-inhibited cells (mediated by $1 \kappa B \alpha \Delta N$ ) leads to massive CD30-induced cell death and accumulation of RIP1 at the cytoplasma membrane in close proximity to the CD30 receptor (right panel). This cell death is abolished by RIP1 inhibition, mediated by RIP1 siRNA or Nec-1, for which reason it might be denoted necroptosis. In addition, CD30induced cell death is also inhibited by the pan-caspase inhibitor z-VAD-fmk, and therefore should be named apoptosis. Our results demonstrate the crucial role of RIP1 in the context of CD30-induced cell death. The model does not cover the entire functional spectrum of RIP1, which is beyond the scope of this work. 
a

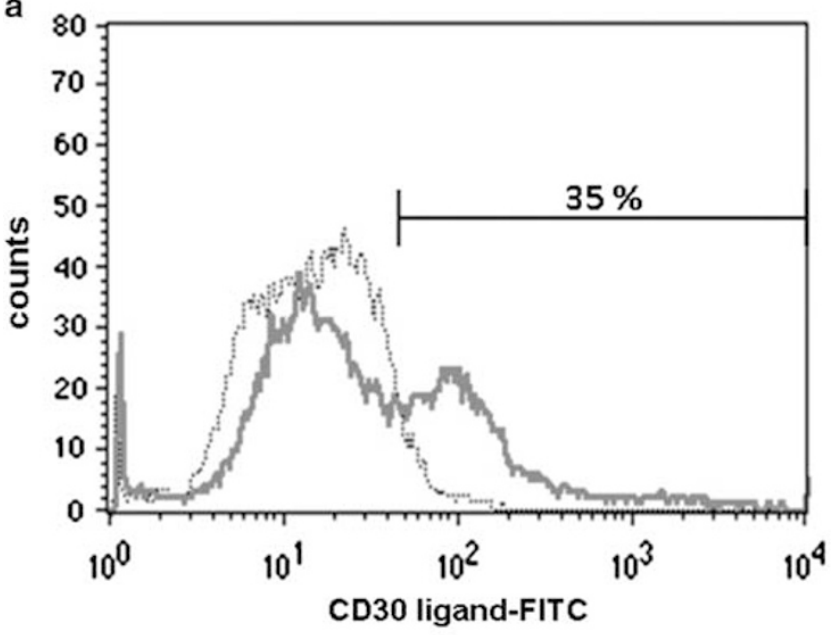

b

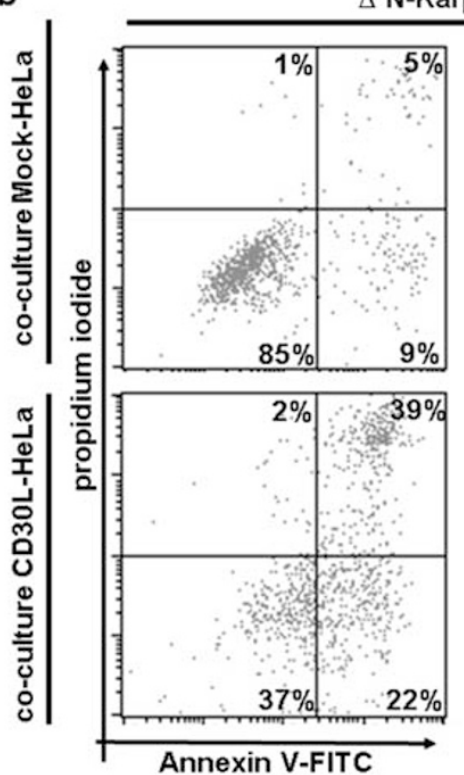

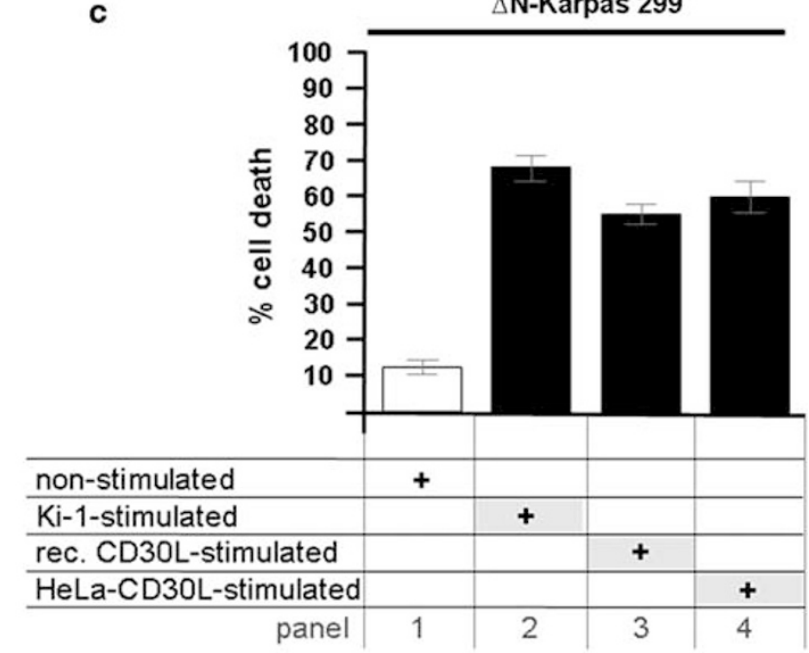
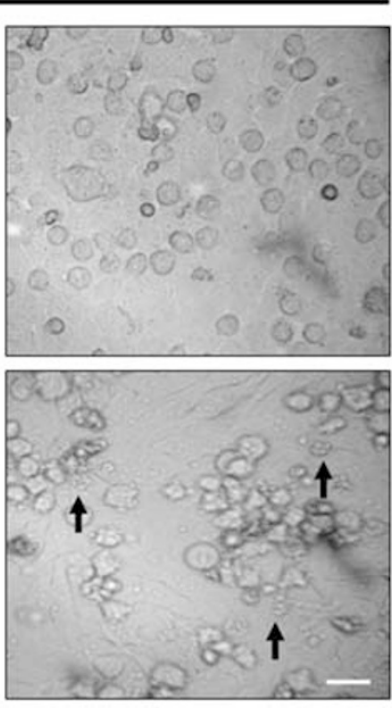

d

A20 TRAF1 WIA CIAP2

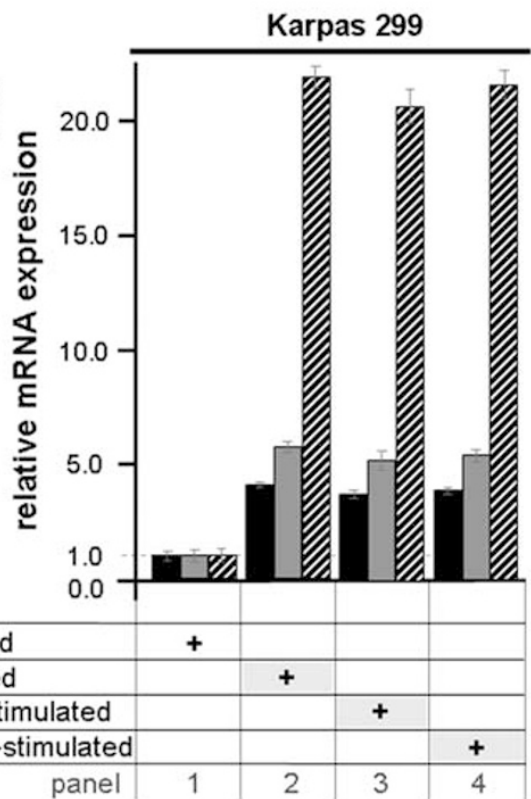

Figure 4 CD30L expression of CD30L-transfected HeLa cells and comparative analysis of Ki-1, recombinant CD30L or HeLa-expressed CD30L-mediated effects. (a) The CD30L expression of CD30L-transfected (thick solid gray line) or mock-transfected HeLa cells (thin dotted line) was analyzed by flow cytometry. The percentage of CD30L-positive HeLa cells ( 35\%) is indicated. (b) $\Delta$ N-Karpas 299 (CD30-positive) were co-cultured with mocktransfected HeLa cells (non-stimulated, upper panel) or co-cultured with CD30L-transfected HeLa cells for 16 h (lower panel). Flow cytometric analysis of Annexin V-FITC/PI-stained cells revealed that CD30 stimulation of $\Delta \mathrm{N}$-Karpas 299 induced $48 \%$ of cell death (left panel). Microscopic analyses confirmed that control-treated cells did not show signs of cell death, whereas CD30-stimulated $\Delta \mathrm{N}$-Karpas 299 cells showed massive induction of cell death (lower right panel, arrows) (Scale bar, $10 \mu \mathrm{m}$ ). (c) Comparative analyses of CD30-induced cell death of $\Delta \mathrm{N}$-Karpas 299 cells, mediated by $16 \mathrm{~h}$ incubation with Ki-1, recombinant CD30L, or CD30L-transfected HeLa. (d) Comparative analyses of CD30-induced A20, cIAP2, and TRAF1 mRNA expression in Karpas 299 cells stimulated by Ki-1, recombinant CD30L, or CD30L-expressing HeLa cells for 16 h. These data and experience of more than a decade revealed that there are no significant differences of CD30 stimulation when comparing the effects of soluble and immobilized agonistic antibodies or soluble recombinant CD30L and cell-bound CD30L. Data of $\mathbf{c}$ and $\mathbf{d}$ are presented as mean \pm s.d. of three experiments.

importance for therapeutic approaches of ALCL patients. Combined $\mathrm{CD} 30$-stimulation/NF $\kappa \mathrm{B}$-inhibition therapy ${ }^{29}$ might only be effective in RIP1 expressing tumor cells. In order to verify the potential correlation of RIP1 and ALK expression, we analyzed gene expression array data of 50
ALCL patient samples that have been obtained from three publicly available data bases (GSE6338, GSE14879, and GSE19069). ${ }^{24-26}$ As depicted in the combined box/dot-plots (Figure 5d), the entire set of 50 samples is clearly split into two groups, based on ALK (probe set 208212_s_at) expres- 
a
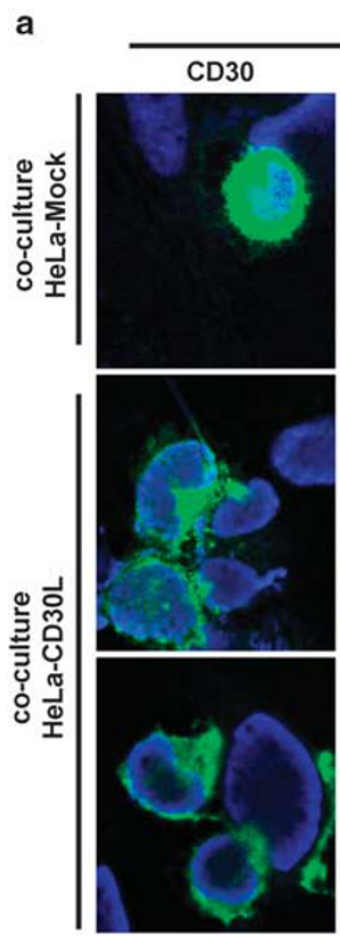

c
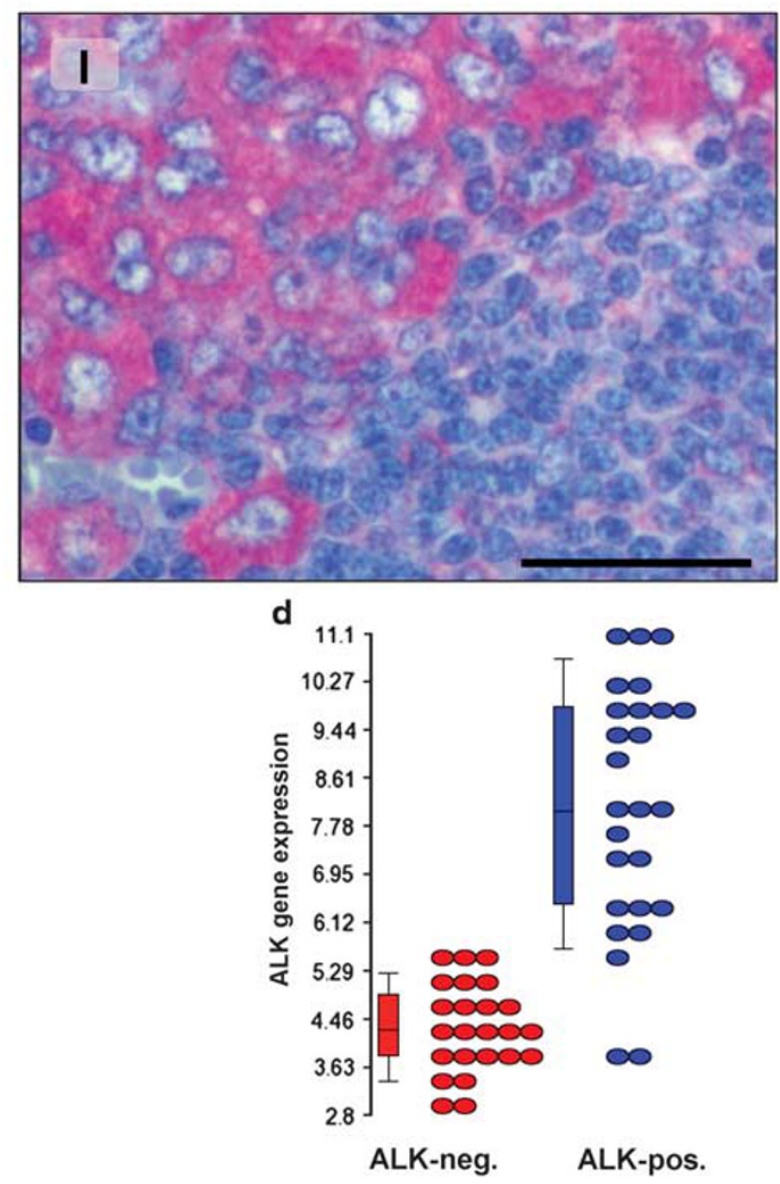

Karpas 299
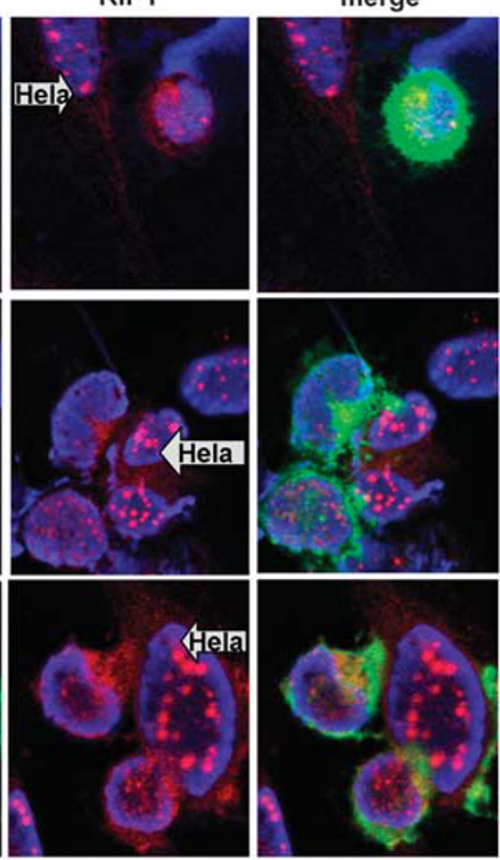
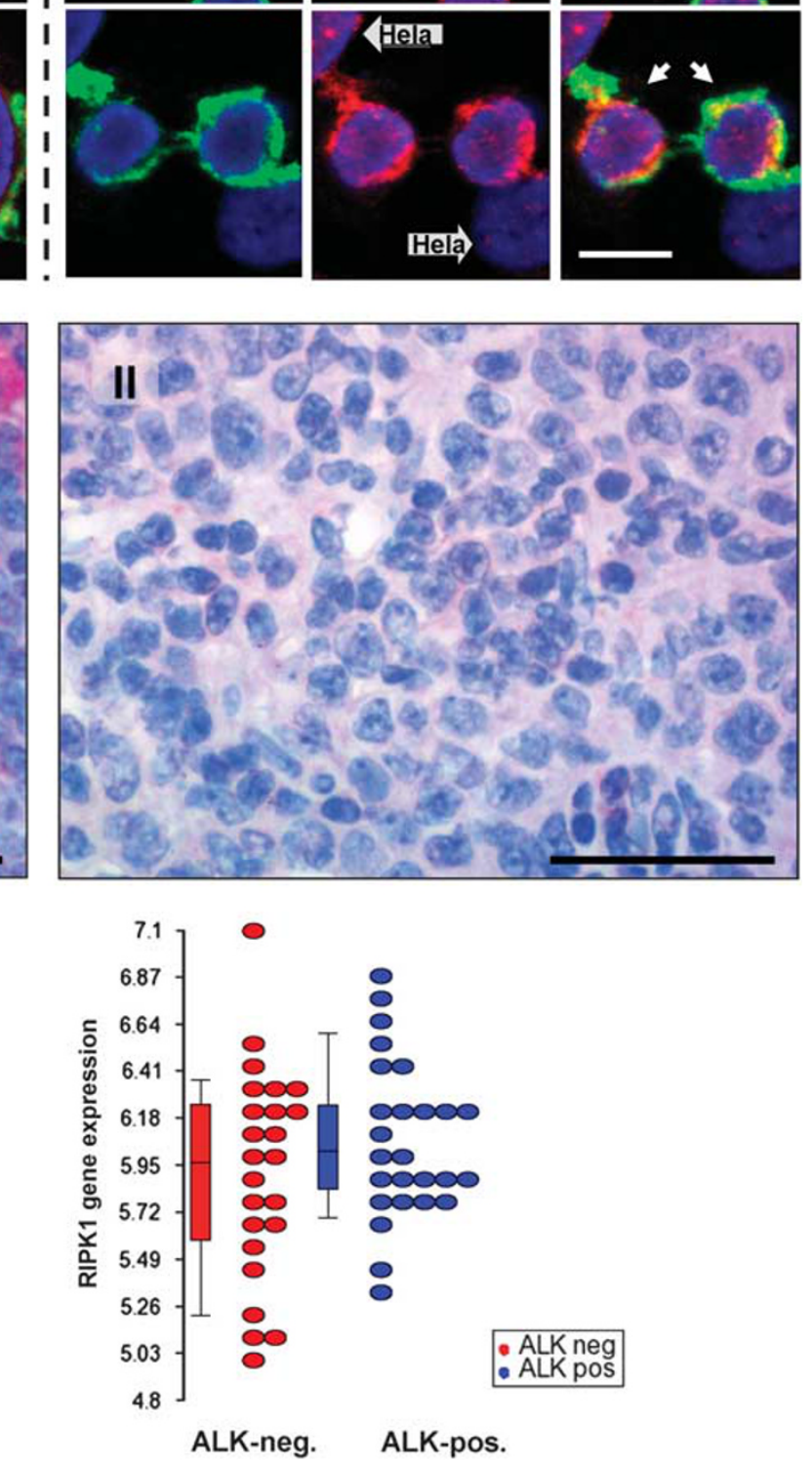
sion $(P=9.56 \mathrm{e}-11)$. On the other hand, RIPK1 expression (probe set 226551_s_at) is not significantly different in ALK-negative and ALK-positive samples $(P=0.507)$.

\section{DISCUSSION}

This is the first report that establishes a link between the death domain (DD)-containing serine/threonine kinase RIP1 and the signaling of CD30, a TNFR without DD. DDs are cytoplasmic stretches of TNFRs like TNFR1, TRAILR, and CD95/Fas that mediate death signals. ${ }^{30}$ We show that RIP1 is crucially involved in CD30-induced cell death, which can be specifically inhibited by RIP1 siRNA or pharmacologically by the allosteric RIP1 kinase inhibitor Nec- $1 .{ }^{17}$ In addition to the specific approaches of RIP1 inhibition, we corroborated our findings by the application of GA. GA induces RIP1 degradation by disrupting the function of the RIP1associating chaperone heat shock protein 90 (Hsp90) but GA is also known to inhibit various proto-oncogenic protein kinases. $^{31}$ Here, we demonstrated GA-mediated RIP1 inhibition and abrogation of CD30-induced cell death.

As inhibition of RIP1 kinase activity by Nec-1 efficiently blocked necroptosis ${ }^{17}$, our data clearly indicate that CD30mediated cell death carries features of necroptosis. ${ }^{32}$ Paradoxically, we further revealed that CD30-induced cell death comes along with increased PARP cleavage and caspase- 8 activation that can be inhibited by the pancaspase inhibitor $z$-VAD-fmk. These results demonstrate that caspase-mediated apoptotic mechanisms also have a role in CD30-mediated cell killing. Therefore, CD30-induced cell death cannot be classified according to Galluzzi et a $l^{32}$ as features of apoptosis and necroptosis appear to be collaborative active under these conditions.

Our findings extend current knowledge and match very nicely with recently published work by Knox et al, ${ }^{8}$ who demonstrated that RIP1 links the immunoregulatory receptor CD40 to apoptotic signaling in carcinomas. Thus, it becomes apparent that not only DD-containing TNFRs but also TRAF domain-carrying TNFRs like CD30 and CD40 use RIP1 for signal transduction.

Originally, RIP1 was considered to constitute an absolute requirement for TNF-mediated $\mathrm{NF} \kappa \mathrm{B}$ activation. ${ }^{33}$ This view is challenged by recent data where cells from $\mathrm{RIP} 1^{-1-}$ knockout mice activated $\mathrm{NF} \kappa \mathrm{B}$ in response to $\mathrm{TNF}^{34}$ These data are in line with our observations. We successfully inhibited RIP1 by siRNA in native ALCL cells, but CD30mediated $\mathrm{NF} \kappa \mathrm{B}$ activation, as revealed by $\mathrm{NF} \kappa \mathrm{B}$ target gene analysis, was not abrogated. Our results clearly indicate that RIP1 is not required for $\mathrm{CD} 30$-mediated $\mathrm{NF} \kappa \mathrm{B}$ activation but instead transmits the $\mathrm{CD} 30$ signal to cell death under $\mathrm{NF} \kappa \mathrm{B}$ inhibited condition. We revealed CD30-mediated canonical and non-canonical NF $\kappa \mathrm{B}$ activation in ALCL cell lines, which is in line with previous publications. ${ }^{4,35}$ In addition, we demonstrated CD30-induced non-canonical NF $\kappa$ B activation and $\mathrm{CD} 30$-induced $\mathrm{Bcl}-3$ expression to occur in both, native Karpas 299 and $\mathrm{NF} \kappa \mathrm{B}$-inhibited $\Delta \mathrm{N}$-Karpas 299 cells. Of note, both, constitutive as well as CD30-induced Bcl-3 expression appears to be lower in constitutively $\mathrm{NF} \kappa \mathrm{B}$ inhibited $\Delta \mathrm{N}$-Karpas 299 cells as compared with native Karpas 299 cells.

Activation of TNFR1 leads to highly complex polyubiquitination of RIP1 by the ubiquitin ligases cIAP1/cIAP2 and TRAF2. The mode of ubiquitination determines whether RIP1 works as a prosurvival scaffold molecule leading to $\mathrm{NF} \kappa \mathrm{B}$ activation or as a kinase that mediates cell death. ${ }^{19,36-38}$ In addition to CD30-regulated NF $\kappa \mathrm{B}$ targets, we further analyzed the expression of the TNFR adapter TRAF2 in the context of CD30 signaling. TRAF2 recruits cIAPs to many of the TNFRs, including CD $40^{39}$ and $\mathrm{CD} 30^{28}$ and it is degraded during CD30 signaling. ${ }^{28}$ We revealed that CD30-induced TRAF2 degradation is more pronounced in $\Delta \mathrm{N}$-Karpas 299 cells as compared with native Karpas 299 cells, pointing out to the importance of $\mathrm{NF} \kappa \mathrm{B}$-driven effects on TRAF2-regulation.

As cIAP2 is induced by CD30 stimulation ${ }^{22,27}$ and represents a RIP1 ubiquitin ligase, ${ }^{18}$ we analyzed its expression in CD30-stimulated and unstimulated Karpas 299 and $\Delta \mathrm{N}$-Karpas 299 cells. We revealed that NF $\kappa \mathrm{B}-$ inhibited ALCL cells constitutively express cIAP2 on a very low level and CD30 stimulation is unable to increase cIAP2 protein expression in these cells. Inhibition of cIAPs by BV6, a small molecule that mimics the antagonistic activity of the second mitochondria-derived activator of caspases (Smac), induced auto-ubiquitination and degradation of cIAPs within minutes. ${ }^{40}$ Inhibition of cIAP1 and cIAP2 sensitized

Figure 5 CD30 stimulation of $\triangle \mathrm{N}$-Karpas 299 cells leads to RIP1/CD30-accumulation, and the demonstration of RIP1 expression in lymph node specimens of ALCL patients. CD30-positive (green fluorescence) ALCL cells (Karpas 299) (a), and constitutively NF $\kappa$ B-inhibited ALCL cells ( $\triangle \mathrm{N}$-Karpas 299) (b), were co-cultured for $2 \mathrm{~h}$ with mock-transfected HeLa (non-stimulated, upper panel) or CD30L-transfected HeLa cells (CD30-stimulated, middle and lower panel). Cells were fixed and stained for CD30 (green signal), RIP1 (red signal) and nuclei (blue signal). Two examples of CD30-stimulated native Karpas 299 (left panel) and $\Delta \mathrm{N}$-Karpas 299 cells (right panel) are depicted (middle and lower panel). The overlay revealed a dramatic increase of CD30-mediated RIP1 accumulation at the membrane, ie, at the CD30 receptor that is demonstrated by a yellow signal (merge panel, white arrows). Mock- and CD30L-transfected HeLa cells (CD30-negative) are indicated by gray arrows (Scale bar, $10 \mu \mathrm{m}$ ). (c) Immunohistological analyses of RIP1 expression in lymph nodes of patients with ALCL. Exemplarily, one RIP1-positive and one RIP1-negative case are shown (Scale bar, $100 \mu \mathrm{m})$. (d) Combined Box/Dot-plots of ALK (probe set 208212_s_at) and RIPK1 gene expression (probe set 226551_s_at) of specimens of 50 ALCL patients that have been classified into 24 ALK-negative and 26 ALK-positive cases, based on immunohistology. ${ }^{24-26}$ These publicly available Affymetrix HG-U133 Plus 2.0 array GEO-data (GSE6338, GSE14879, and GSE19069) have been analyzed by Partek Genomic Suite Software. ALCL cases can be subdivided into two significantly different groups, based on ALK expression $(P=9.56 \mathrm{e}-11)$ (left panel). RIPK1 expression is not significantly different in ALK-negative and ALK-positive samples $(P=0.507)$ (right panel). 
cells to TNF by the formation of a RIP1-dependent caspase8 -activating complex and culminated in cell death. ${ }^{9}$ Therefore, cIAPs and RIP1 represent an 'intimate couple' with deep impact on TNFR-signaling events. ${ }^{41}$ In terms of DD-TNFRs like TNFR1, low IAP expression rendered cells sensitive to TNF-induced cell death. ${ }^{18}$ Despite the fact that CD30 does not belong to this group of TNFRs, we reasoned whether low cIAP2 expression as measured in $\triangle \mathrm{N}$-Karpas 299 cells is involved in the switching the CD30 signal to cell death. Of note, neither CD30 nor TNF stimulation of native Karpas 299 leads to apoptosis when cells are grown in complete medium with normal serum concentrations. Here, we successfully inhibited IAP expression of Karpas 299 cells by BV6 but neither CD30 nor TNF stimulation induced cell death in these cells. We further revealed that BV6 treatment slightly increased cell death and constitutive expression of the bona fide $\mathrm{NF} \kappa \mathrm{B}$ target $\mathrm{A} 20 / \mathrm{TNFAIP} 3$. Of note, IAP inhibition did not abolish CD30-induced upregulation of A20. However, our data did not disclose a key role for cIAP2 in the context of CD30-induced cell death.

Our findings meet published data demonstrating CD30-induced cell death in vitro and in a human Hodgkin lymphoma xenograft model by Bortezomib-mediated proteasome inhibition. ${ }^{5}$ Bortezomib is a potent and reversible proteasome inhibitor with clinical efficacy ${ }^{29}$ that leads to blockage of $\mathrm{I} \kappa \mathrm{B} \alpha$ degradation/NF $\kappa \mathrm{B}$ activation. Therefore, both aspects of our in vitro model, ie, $\mathrm{NF} \kappa \mathrm{B}$ inhibition and CD30 stimulation of CD30-positive tumor cells, are applicable to the in vivo situation. However, only patients with RIP1 expression might benefit from bortezomib-mediated $\mathrm{NF} \kappa \mathrm{B}$ inhibition paralleled by CD30 stimulation. It is, therefore, conceivable to determine RIP1 expression of ALCL tumor samples by immunohistology in order to identify RIP1positive patients that should be eligible for combined CD30antibody/NF $\kappa \mathrm{B}$-targeted therapy. ${ }^{42,43}$ To test a possible correlation of RIP1 and ALK expression we analyzed previously published ALCL gene-expression array data sets that covered 50 ALCL cases, where 26/24 cases have been defined to be ALK-positive/-negative, respectively. ${ }^{24-26}$ Based on our analysis of these 50 ALCL samples we conclude that ALK- and RIP1-expression do not correlate $(P=0.507)$. Therefore, we cannot convey an impact of RIP1 expression on the prognosis of ALK-positive or ALK-negative ALCL.

In vivo, $\mathrm{CD} 30$ stimulation is mediated by the interaction of CD30-positive and CD30L-positive cells. ${ }^{43}$ Here, we established and functionally validated a cell-based strategy of CD30 stimulation that most closely mimics the physiological situation. Different cell-based CD30L-expressing systems have been applied in the past, first by Smith et al ${ }^{44}$ and Csomos, ${ }^{28}$ using CV1/EBNA cells and $\mathrm{CHO}$ cells, respectively. We established a HeLa-based CD30L expression system to additionally investigate CD30-mediated changes of subcellular protein distribution by confocal laser scanning microscopy. This led us to demonstrate (i) a CD30-induced shift of RIP1 to the cytoplasma membrane and (ii) the
RIP1/CD30 co-localization in CD30-stimulated NF $\kappa$ Binhibited ALCL cells. These CD30-induced intracellular changes remind of 'capping' ${ }^{45}$ or uropod-like structures that are formed following cytokine-mediated stimulation of T-lymphocytes where flotillin proteins constitute microdomains in the plasma membrane. ${ }^{46}$

In conclusion, we identified RIP1 as a new and critical regulator of CD30 signaling. Moreover, RIP1 is important for $\mathrm{CD} 30$-induced cell death in $\mathrm{NF} \kappa \mathrm{B}$-deficient CD30-positive cells. Interestingly, this RIP1-mediated cell death carries features of both, apoptosis and necroptosis. This notion is very important for therapeutic considerations, as CD30-induced cell death can only be evoked in RIP1 expressing cells in conjunction with $\mathrm{NF} \kappa \mathrm{B}$ inhibition.

\section{ACKNOWLEDGEMENTS}

We are grateful to Dr Dido Lenze for her excellent help with Partek softwarebased CEL-file data analysis of Affymetrix Human Genome U133Plus 2.0 Arrays. This work was supported by the Deutsche Forschungsgemeinschaft (DU370/3-1). The IAP-antagonist (Smac mimetic) BV6 was kindly provided by Dr Vucic, Genentech, USA.

\section{DISCLOSURE/CONFLICT OF INTEREST}

The authors declare no conflict of interest.

1. Chiarle R, Podda A, Prolla G, et al. CD30 in normal and neoplastic cells. Clinlmmunol 1999;90:157-164.

2. Sievers EL, Senter PD. Antibody-drug conjugates in cancer therapy. Ann Rev Med 2012;64:15-29, 16.11-16.15.

3. Hubinger G, Muller E, Scheffrahn I, et al. CD30-mediated cell cycle arrest associated with induced expression of p21(CIP1/WAF1) in the anaplastic large cell lymphoma cell line Karpas 299. Oncogene 2001;20:590-598.

4. Hirsch B, Hummel M, Bentink S, et al. CD30-induced signaling is absent in Hodgkin's cells but present in anaplastic large cell lymphoma cells. Am J Pathol 2008;172:510-520.

5. Boll $B$, Hansen $H$, Heuck $F$, et al. The fully human anti-CD30 antibody 5F11 activates NF-\{kappa\}B and sensitizes lymphoma cells to bortezomib-induced apoptosis. Blood 2005;106:1839-1842.

6. Grell M, Zimmermann G, Gottfried E, et al. Induction of cell death by tumour necrosis factor (TNF) receptor 2, CD40 and CD30: a role for TNF-R1 activation by endogenous membrane-anchored TNF. EMBO J 1999;18:3034-3043.

7. Festjens N, Vanden Berghe T, Cornelis S, et al. RIP1, a kinase on the crossroads of a cell's decision to live or die. Cell Death Differ 2007; 14:400-410.

8. Knox PG, Davies CC, loannou M, et al. The death domain kinase RIP1 links the immunoregulatory CD40 receptor to apoptotic signaling in carcinomas. J Cell Biol 2011;192:391-399.

9. Darding M, Meier P. IAPs: guardians of RIPK1. Cell Death Differ 2012;19:58-66.

10. Micheau O, Tschopp J. Induction of TNF receptor I-mediated apoptosis via two sequential signaling complexes. Cell 2003;114:181-190.

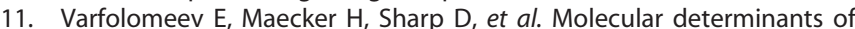
kinase pathway activation by Apo2 ligand/tumor necrosis factorrelated apoptosis-inducing ligand. J Biol Chem 2005;280:40599-40608.

12. Lavrik IN, Mock T, Golks A, et al. CD95 stimulation results in the formation of a novel death effector domain protein-containing complex. J Biol Chem 2008;283:26401-26408.

13. Vandenabeele P, Galluzzi L, Vanden Berghe $T$, et al. Molecular mechanisms of necroptosis: an ordered cellular explosion. Nat Rev Mol Cell Biol 2010;11:700-714.

14. Bertrand MJ, Vandenabeele P. The ripoptosome: death decision in the cytosol. Mol Cell 2011;43:323-325.

15. Christofferson DE, Yuan J. Necroptosis as an alternative form of programmed cell death. Curr Opin Cell Biol 2010;22:263-268. 
16. Moquin D, Chan FK. The molecular regulation of programmed necrotic cell injury. Trends Biochem Sci 2010;35:434-441.

17. Degterev A, Hitomi J, Germscheid M, et al. Identification of RIP1 kinase as a specific cellular target of necrostatins. Nat Chem Biol 2008;4: 313-321.

18. Varfolomeev E, Goncharov T, Fedorova AV, et al. c-IAP1 and c-IAP2 are critical mediators of tumor necrosis factor alpha (TNFalpha)-induced NF-kappaB activation. J Biol Chem 2008;283:24295-24299.

19. Bertrand MJ, Milutinovic S, Dickson KM, et al. CIAP1 and CIAP2 facilitate cancer cell survival by functioning as E3 ligases that promote RIP1 ubiquitination. Mol Cell 2008;30:689-700.

20. Declercq W, Vanden Berghe T, Vandenabeele P. RIP kinases at the crossroads of cell death and survival. Cell 2009;138:229-232.

21. Hirsch B, Grunbaum M, Wagner $F$, et al. A novel A20 (TNFAIP3) antibody (Ber-A20) can be used to detect unmutated $A 20$ by immunohistology. Histopathology 2012;60:E19-E27.

22. Durkop H, Hirsch B, Hahn C, et al. CIAP2 is highly expressed in Hodgkin-reed-sternberg cells and inhibits apoptosis by interfering with constitutively active caspase-3. J Mol Med 2006;84:132-141.

23. Livak KJ, Schmittgen TD. Analysis of relative gene expression data using real-time quantitative PCR and the 2(-Delta Delta C(T)) Method. Methods 2001;25:402-408.

24. Piccaluga PP, Agostinelli C, Califano A, et al. Gene expression analysis of peripheral T cell lymphoma, unspecified, reveals distinct profiles and new potential therapeutic targets. J Clin Invest 2007;117:823-834.

25. Eckerle S, Brune V, Doring C, et al. Gene expression profiling of isolated tumour cells from anaplastic large cell lymphomas: insights into its cellular origin, pathogenesis and relation to Hodgkin lymphoma. Leukemia 2009;23:2129-2138.

26. Iqbal J, Weisenburger DD, Greiner TC, et al. Molecular signatures to improve diagnosis in peripheral T-cell lymphoma and prognostication in angioimmunoblastic T-cell lymphoma. Blood 2010;115:1026-1036.

27. Hubinger G, Schneider C, Stohr D, et al. CD30-induced up-regulation of the inhibitor of apoptosis genes CIAP1 and CIAP2 in anaplastic large cell lymphoma cells. Exp Hematol 2004;32:382-389.

28. Csomos RA, Wright CW, Galban $\mathrm{S}$, et al. Two distinct signalling cascades target the NF-kappaB regulatory factor C-IAP1 for degradation. Biochem J 2009;420:83-91.

29. Shahshahan MA, Beckley MN, Jazirehi AR. Potential usage of proteasome inhibitor bortezomib (Velcade, PS-341) in the treatment of metastatic melanoma: basic and clinical aspects. Am J Cancer Res 2011:1:913-924.

30. Mahmood Z, Shukla Y. Death receptors: targets for cancer therapy. Exp Cell Res 2010;316:887-899.
31. Neckers L, Workman P. Hsp90 molecular chaperone inhibitors: are we there yet? Clin Cancer Res 2012;18:64-76.

32. Galluzzi L, Vitale I, Abrams JM, et al. Molecular definitions of cell death subroutines: recommendations of the Nomenclature Committee on Cell Death 2012. Cell Death Differ 2012;19:107-120.

33. Ea CK, Deng L, Xia ZP, et al. Activation of IKK by TNFalpha requires sitespecific ubiquitination of RIP1 and polyubiquitin binding by NEMO. Mol Cell 2006;22:245-257.

34. Wong WW, Gentle IE, Nachbur U, et al. RIPK1 is not essential for TNFR1-induced activation of NF-kappaB. Cell Death Differ 2010; 17:482-487.

35. Nishikori $\mathrm{M}$, Ohno $\mathrm{H}$, Haga $\mathrm{H}$, et al. Stimulation of CD30 in anaplastic large cell lymphoma leads to production of nuclear factor-kappaB p52, which is associated with hyperphosphorylated Bcl-3. Cancer Sci 2005;96:487-497.

36. Varfolomeev E, Vucic D. (Un)expected roles of C-IAPs in apoptotic and NFkappaB signaling pathways. Cell Cycle 2008;7:1511-1521.

37. Wajant $\mathrm{H}$, Scheurich P. TNFR1-induced activation of the classical NF-kappaB pathway. FEBS J 2011;278:862-876.

38. Gerlach B, Cordier SM, Schmukle AC, et al. Linear ubiquitination prevents inflammation and regulates immune signalling. Nature 2011;471:591-596.

39. Vallabhapurapu S, Matsuzawa A, Zhang W, et al. Nonredundant and complementary functions of TRAF2 and TRAF3 in a ubiquitination cascade that activates NIK-dependent alternative NF-kappaB signaling. Nat Immunol 2008;9:1364-1370.

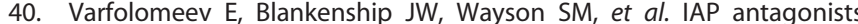
induce autoubiquitination of c-IAPs, NF-kappaB activation, and TNFalpha-dependent apoptosis. Cell 2007;131:669-681.

41. Darding M, Meier P. IAPs: guardians of RIPK1. Cell Death Differ 2011:19:58-66.

42. Rabson $A B$, Weissmann $D$. From microarray to bedside: targeting NF-kappaB for therapy of lymphomas. Clin Cancer Res 2005;11:2-6.

43. Younes A. CD30-targeted antibody therapy. Curr Opin Oncol 2011; 23:587-593.

44. Smith CA, Gruss HJ, Davis T, et al. CD30 antigen, a marker for Hodgkin's lymphoma, is a receptor whose ligand defines an emerging family of cytokines with homology to TNF. Cell 1993;73: 1349-1360.

45. Le Tourneau A, Audouin J, Diebold J, et al. Large anaplastic cell Ki-1 positive malignant lymphoma with peculiar endocytotic vacuoles. Pathol Res Pract 1990;186:784-792, discussion 792-784.

46. Otto GP, Nichols BJ. The roles of flotillin microdomains - endocytosis and beyond. J Cell Sci 2011;124(Pt 23):3933-3940. 